\title{
High School Students in Trinidad: Views on HIV/AIDS and Sexual Activity
}

\author{
Beverly Foster-Hinds ${ }^{1}$, Randall Thompson ${ }^{1} \&$ Elizabeth Thompson ${ }^{1}$ \\ ${ }^{1}$ School of Advanced Studies, University of Phoenix, USA \\ Correspondence: Randall Thompson, School of Advanced Studies, University of Phoenix, USA. Tel: \\ 1-847-344-0643. E-mail: randalliz@sbcglobal.net
}

Received: May 14, 2015

doi:10.5539/ijps.v7n3p1
Accepted: June 16, 2015 Online Published: August 12, 2015

URL: http://dx.doi.org/10.5539/ijps.v7n3p1

\begin{abstract}
In this qualitative exploratory study, we explored the views of high school students on how the incidence of HIV/AIDS in Trinidad had influenced their personal experiences of engaging or not engaging in sexual activities and their knowledge about the prevention and spread of HIV/AIDS. We conducted face-to-face interviews with 46 students (23 males and 23 females) who ranged in age from 15 to 19. Four major themes emerged: (a) feelings of how HIV/AIDS affected their lives, (b) deciding to abstain from sexual activity, (c) protecting self from HIV/AIDS, and (d) reasons for engaging in sexual activities. Adolescence is a high-risk time for HIV transfer by sexual exploration and experimentation. In the present study $33 \%$ of females and $24 \%$ of males indicated that they were sexually active. Two-thirds of the males but only one-third of the females reported using condoms all the time. Of the 12 sexually active students who did not use condoms all the time, five had never been tested for HIV/AIDS, which put them at risk for being infected with the HIV virus or other diseases such as gonorrhea, syphilis, and human papilloma virus (HPV) that can be spread to another person during sexual activity.
\end{abstract}

Keywords: youth at-risk, Trinidad, HIV/AIDS, sexual activity, students, high school

\section{Introduction}

In 2014, UNAIDS Gap Report indicated that 5\% of people with HIV in the Caribbean region lived in the twin island state of the Republic of Trinidad and Tobago. By the end of 2010, an estimated 23 thousand persons were living with HIV/AIDS in Trinidad giving a prevalence rate of $1.5 \%$ (Office of the Prime Minister, 2010). Females comprised $74 \%$ in the 15-24 year age group. The most at risk populations for HIV/AIDS in Trinidad are men who have sex with men, sex workers, substance abusers, and youth who engage in unprotected sex (Office of the Prime Minister, 2010). In Trinidad, the incidence of HIV/AIDS has been highest among persons aged 15-49 (National AIDS Coordinating Committee [NACC], 2009). Stigma and discrimination against people living with the disease, multiple sex partnering, and myths and misinformation surrounding key issues, such as condom use, have contributed to the HIV/AIDS epidemic in Trinidad (UNAIDS, 2014).

Adolescence is a high-risk time for HIV transfer if sexual exploration and experimentation occurs (Selikow, Ahmed, Fisher, Matthews, \& Mukoma, 2009). Early initiation of sexual activity has a linkage to HIV/AIDS infection because young adolescents have little knowledge of HIV prevention and condom use (Bongaarts, 2007). The HIV/AIDS virus exposes persons to opportunistic infections by first undermining then eradicating the body' $\mathrm{s}$ immune system eventually leading to death without treatment. Youth who engage in unprotected sex have been identified as an at risk population in Trinidad (Office of the Prime Minister, 2010). However, little research exists on their views and perceptions of how HIV/AIDS has affected their sexual activity. The purpose of this qualitative research study was to explore the views of high school students on how the incidence of HIV/AIDS in Trinidad had influenced their personal experiences of engaging or not engaging in sexual activities and their knowledge about the prevention and spread of HIV/AIDS.

\section{Method}

We recruited participants who volunteered from four schools in Trinidad: two were faith-based, one public, and one private. We conducted face-to-face structured interviews with open-ended questions with 46 students who ranged from 15 to 19 years of age. Twenty-three participants were female and 23 participants were male. 
Students under 18 were only able to participate if they received parental consent along with giving their own consent. Although students in some cases appeared willing, obtaining consent from their parents was not forthcoming. The necessary permissions to conduct the study were obtained from University of Phoenix' $s$ Institutional Review Board, Ministry of Education, Trinidad and Tobago, and the participating schools.

We developed four areas of interest to explore: how has the incidence of HIV/AIDS in Trinidad influenced sexual behavior of high school students? What reasons do high school student give for abstaining from sexual activities? What reasons do high school students give for engaging in sexual behaviors? What precautions do high school students take to prevent HIV/AIDS?

\section{Data Collection}

We collected data through transcriptions of audiotaped face-to-face interviews held at four high schools on the school compound during regular hours. The one-on-one interviews allowed participants to speak freely on a sensitive topic and permitted in-depth questioning and rich data collection. The success of the study required that participants were comfortable to provide responses on their sexual behavior in response to HIV/AIDS. The face-to-face interview, while time-consuming, allowed students to be comfortable in a private room while they discussed a sensitive topic, rather than in a group setting.

The students were encouraged at the beginning of each interview to relax and talk freely regarding the ways HIV/AIDS had influenced their lives. At the end of each interview, which lasted approximately forty-five minutes, each student was debriefed to ensure that they were in no way uncomfortable. We did member checking at the end of each interview to verify participants' responses. The debriefing session also allowed participants to ask any questions that they might have had and to receive copies of information on HIV/AIDS testing sites and on HIV/AIDS prevention.

\section{Data Analysis}

Data analysis involved qualitative coding to interpret student responses to open-ended interview questions. The results of the one-on-one interviews were analyzed using NVivo10 qualitative software to assist in defining categories that emerged from the data. We developed codes based on participants' responses and did not force into preconceived categories. Data were compared in an iterative process to identify emergent themes and to generate insights from student responses to the interview questions.

Focused coding was used to further analyze line-by-line coding and thereby identify the most frequent and significant codes and to re-categorize the codes into themes. From the analysis, four major themes emerged: (a) feelings of how HIV/AIDS affected their lives; (b) deciding to abstain from sexual activity; (c) protecting self from HIV/AIDS; and (d) reasoning for having sex.

\section{Results}

\subsection{Feelings of How HIV/AIDS Affected Their Lives}

Twenty-nine of the 46 participants reported that HIV/AIDS had not affected their life in any way. Twenty participants indicated that they did not know anyone with HIV/AIDS and not knowing someone seemed to provide a shield of immunity even though 15 of the participants were sexually active. M42 stated, "Not really affected, don't know anyone with HIV." F35 said, "Hasn't affected me once I know I am sexually active, I go and take a test. Don't know anyone with HIV." Twelve (26\%) participants felt personally affected by HIV/AIDS. M4 talked about an uncle who died from AIDS.

I was never in a relationship with anyone who had it. My uncle died with HIV/AIDS last year. I was really close and his son now lives with us as his mother has it too. His mom visits every now and again. She is in good condition. Uncle never told me, my mom told me. Even though uncle had HIV/AIDS never saw him any different.

The existence of HIV/AIDS frightened F41 who had a godmother with the disease. F41 said, "Frighten because condoms come like a plastic bag going up inside you. If it didn't have HIV wouldn't have to use condom and free-way (no condoms) would be better." Sexual activity and starting a relationship were also reasons cited for HIV/AIDS having an effect on one's life. F19, who linked getting married with starting sexual activity, commented on the effect of HIV/AIDS as follows:

Of course when looking for a marriage mate and you know this exists, you would want to take the precaution of taking the test before marriage, even though you trust person still want to do the test. Don't know anyone with HIV/AIDS. 
Even though some participants were sexually active and saw HIV/AIDS as affecting their lives, this did not necessarily mean that they used condoms all the time or had even ever been tested. F31, a sexually active female, explained while acknowledging that HIV/AIDS had an effect on her life.

Current partner got tested, doesn't have AIDS. Used condoms half of the time. Didn't always use condoms, started to use because never know what can happen and can also get other diseases or pregnant, as got more aware started to use condoms. Never been tested.

Other participants indicated that with the existence of HIV/AIDS they used condoms all the time and got tested every three or four months. F38, who had indicated that HIV/AIDS affected her life, responded to the question regarding condom usage as follows:

Used condoms all the time. I have a stepfather who know me and I used to talk to him and he used to buy these things for me and say: If you have to do it use this. We go for test every six months.

\subsection{Deciding to Abstain from Sexual Activity}

Three major reasons were given for abstaining from sexual activity: (a) upholding religious values $(n=10)$, (b) upholding personal values $(n=8)$, and (c) influence of parents $(n=9)$. Ten students referred to upholding religious values as the reason for abstaining from sexual activity. Seven male participants indicated that the reason that they abstained from having sex was because of religious teaching of no sex before marriage. The interviewees were active church members and belonged to religions including Catholic, Pentecostal, and Jehovah Witness. M43 noted that he regularly attended church and stated, "I am a church person, go to Catholic church regular, no sex before marriage. I am comfortable with decision; you need to make a decision. Sometimes you get tempted, but I believe is best way, no sex." M3 indicated, "Not sexually active and never have been. I have a girlfriend who is spiritual minded and thinks like me. I am a Christian." M1 reinforced that his Christian religion was the reason that he had not had sex and stated the following: "I believe (I am a Christian) that people who usually get AIDS are those who are not married, they get AIDS as punishment for having sex out of marriage." M1 was the only person of the 46 interviews who indicated that HIV/AIDS was punishment for having sex out of marriage. M15 indicated his reason for abstaining from sex was as follows: "My religion (Muslim no sex before marriage) and way brought up (father a tough one)."

F19 indicated the main reason she was not sexually active was because she wanted to please her God and abstain from sex before marriage. F18 indicated that she has a strong Hindu background and wanted to keep herself until after marriage. F12 stated, "Mainly religion (Pentecostal), don' $t$ think for me just yet."

Eight students indicated they were upholding personal values by abstaining from sexual activity. Of this number, three were males and five were females. Although participants indicated that it was their personal value system, which made them decide to abstain from sex, from the comments made, religion also was an influence for some participants. F11 indicated, "My upbringing and personal choice not to have sex before I get married and to find right person. Always attended religious schools. Always had guidance and people to mold me to stay chaste until I am married." F18 and F12 reinforced that religion affected their intention to abstain. F18 commented, "Because I have values and my parents did not raise us in this manner of just sleeping around. I am a Hindu." F23 indicated, "From since I small I say I am waiting until I meet the right person, finish school. I just decided that, not involved in any church." M26 also indicated that he made the decision to abstain before marriage, he was not involved in any church, and he thought that HIV was a serious issue.

Four males and five females indicated their parents influenced their decisions to abstain from having sex. Participants indicated that closeness of their family unit, along with discussions with parents or family were important in their decision to abstain from sexual activity. Some participants indicated their families had high expectations of them, which affected their decisions. The guidance provided by their family was valuable and pivotal in their decisions regarding sexual activity. F37 indicated the following, "Grandparents saying don't have sex before marriage and everyone telling me all STDs around, I say not ready for this. Decided to delay until marriage-not right now." M2 emphasized the important role his parents played and stated,

Parents spoke about HIV/AIDS when I was twelve-talked first about sex and then said shouldn't have sex before marriage and one of diseases can get is AIDS. It was important that my parents spoke to me as I know what to do and what not to do.

\subsection{Protecting Self from HIV/AIDS}

Of the 46 participants, 26 (11 males and 15 females) admitted to being sexually active at the time when the interviews were conducted. Five female participants (33\% of those sexually active) and 7 males (64\% of those sexually active) indicated that they used condoms all the time. Participants who used condoms all the time 
indicated they were unwilling to take any risk, but 50\% admitted that they were not $100 \%$ confident of the protection offered by condoms against contracting HIV/AIDS. F35 commented, "I always used to be frightened of that disease and so I always used condoms." M44 commented, "I use protection right through; not 100\% comfortable with feeling of condoms but comfortable using it." F38 commented, "Used condoms all the time. Not confident because condoms not 100\%."

Twelve participants indicated they used condoms most of the time ( 2 males and 10 females). F30 indicated that she started to use condoms when she became more aware of HIV/AIDS. F34 commented, "In previous relationship had sex a few times without condoms. Don't want to take that risk. The person I am with now I told him this and that I want to go and take a test." Eleven of the 12 participants who used condoms most of the time (92\%) acknowledged that there was risk involved in not using condoms. "Sometimes use condoms, other times put self at risk" (F36). F21 commented, "Use condoms-most of the time. Never been tested nor partner. Does double up - use two condoms at once to feel more secure."

Fifteen of the 26 sexually active participants (57\%) indicated that they had been tested for HIV at least once. Of the 15 sexually active participants, four were males and 11 were females. Participants tested for HIV in conjunction with using condoms and M13 even considered testing as a way to maintain the integrity of the relationship. Fifty-three percent of sexually active participants also went together to have the HIV test conducted. F39 commented, "Use condoms sometimes. Had test last year by myself." F33 commented, "We use condoms all the time. Get tested together, we always maintained this." M13 commented, "We had AIDS test. Every three months we are going for HIV test, also helps to keep the integrity of the relationship. I don't sleep around." Participants also commented that anyone under 18 needed to have adult permission to be tested, which caused some participants not to get tested. F9 commented as follows:

I go to the testing center with my boyfriend to get tested. People don't go because they don't have support. If under 18 , have to go with an adult to get tested. If you want to do the family planning program, you can be under 18 and go without parental consent.

Nine sexually active participants (35\%) indicated they had never been tested for HIV/AIDS. Five of these participants were male and four were female. Some participants indicated that they use condoms all the time and never been tested. M29 commented, "Used condoms all the time. Never been tested." Of the 12 participants who used condoms most of the time; five had never been tested. F31, commented, "Current partner got tested, doesn't have AIDS. Use condoms half of the time. When didn't use condoms, pull out mostly. Never been tested."

\subsection{Reasoning for Having Sex}

The two primary reasons for engaging in sexual activity were personal decision $(n=17)$ and external pressure $(n$ $=8)$. Of the 46 persons interviewed $17(37 \%)$ indicated that they had sex based on their own decision and felt no external pressure in making that decision. Of the 17 persons, $10(59 \%)$ were female and seven (42\%) were male. Some of the reasons given by participants were that they felt ready, love, and curiosity. Seven of the 17 participants (41\%) indicated they felt ready to have sex. F32 commented, "Felt I was ready to have sex, knew person a long time and he never asked or pressured me. I was 18 years." M45 and M27 indicated the following; respectively, "Just a natural thing, hearing friends talk about it. Felt ready. Made decision partner and I both ready." M29 commented, "When I reached a certain age wasn't planned-15 years or so I decided to have sex. At certain point happy in relationship. Not sexually active right now."

Four female participants indicated they made the decision to have sex based on love. F38 commented, "Decided because of love. I guess was love." F35 participant commented she was looking for love and found someone to show her that love:

I was about 13 or 14 (used condoms) years when I lost my virginity. They say home does have a big effect, mother putting you down and you find someone to show love only had sex once. Two years after that in a relationship for one year and four months and then broke up. Got involved with second person because loved him.

Three persons ( 2 males and1 female) cited curiosity as the reason that they became sexually active. F34 commented as follows:

Was curious, wanted to know what it was about because I heard people talking about it. So I play farse and went and see. It should not have happened at such a young age thought I would be about 25 . In relationship now with another person. (Note: Play farse is a local phrase meaning going to investigate or to do something that is not of your concern.) 
Eight persons (17\%) indicated they became sexually active because they felt pressured to do so. Six of these respondents were female and two were male. Female participants indicated they became sexually active to keep the person who was showing them love; in two instances, the girls were in unstable family relationships. F9 commented, "Got sexually active because of insecurity, didn't want the person showing me love to leave me. Grew up in unstable circumstances. Not smart choice at the time was 15. Relationship lasted a year."

F21 commented as follows, "My friend made me get involved, she told me about it and I was having problem in my relationship. In order to save relationship had sex with person, I was 14." F22 commented,

Happened out of stress. Stress how father died and then stepfather came in and how he was talking to me. Something happened with me and my mother and I responded like that, after disappointed in myself. Spoke to mother afterwards and she talked about diseases going around and to be careful.

Peer pressure also played a role in persons being sexually active. M16 indicated the following.

Sexually active through peer pressure. Few months after realized wrong thing to do, was unprotected sex as well. In forms four to five everyone started to get girlfriends and talk about how good sex was. I started to talk to a girl, got girl in form five and had sex last year. (Note: Form is the word used to refer to what grade or class the student is attending at school.)

\section{Discussion}

The scope of this qualitative study was limited to 15-19 year old students enrolled at four schools in Trinidad. The exploration focused on students' views and perceptions concerning HIV/AIDS and sexual activity. Slightly more than one-half (57\%) of the 46 student participants, admitted to being sexually active. Two-thirds of the sexually active males and one-third of the females reported using condoms all the time. Of the 12 students who did not use condoms all the time, five had never been tested for HIV/AIDS, which put them at risk for being infected with the HIV virus or other diseases such as gonorrhea, syphilis, and human papilloma virus (HPV) that can be spread to another person during sexual activity. Participants who used condoms all the time indicated that were unwilling to take any risk, but one-half of the students admitted that they were not $100 \%$ confident of the protection offered by condoms against contracting HIV/AIDS. Condoms can break during vaginal intercourse and more potential exists for breakage during anal sex. One participant talked about doubling up the condom for additional protection.

As stated in the literature, young people are not consistent with using condoms, which puts them at higher HIV risk (Haque \& Soonthorndhada, 2009; Romero, Ellis, \& Gurman, 2012; World Health Organization, 2006). A UNAIDS analysis reported that consistent and correct condom use has a $90 \%$ success rate in stopping HIV/AIDS transmission (Sinding, 2005). The intention to use condoms is influenced by the perceived level of control, the norms of society, and the prevailing attitudes on condom use (Schaalma et al., 2009). Disparity exists between condom use and the knowledge on how condoms aid in HIV/AIDS prevention (Halperin et al., 2011). Ten of the 12 participants that used condoms most of the time were female. Adolescent girls who have sexual relationships with older men use condoms less than those girls do in relationships with adolescent boys because older men may have more power due to their finances or age (DiClemente et al., 2002). Condom use is negatively affected by beliefs such as pleasure reduction when using condoms, embarrassment to purchase, stigmatization, and poor usage knowledge. If a partner supports condom use, this increases the use of condoms (Benefo, 2010).

Fifteen of the 26 sexually active participants (males $=4$; females $=11$ ) indicated that, they had been tested for HIV at least once. Fifty-three percent of the sexually active participants also went together with their sexual partner to have the HIV test done. Participants also commented that anyone under 18 needed to have adult permission to be tested, which prevented some participants from being tested. Nine sexually active participants indicated they had never been tested for HIV/AIDS. Encouraging young people to know their HIV/AIDS status through voluntary counseling and testing (VCT) may assist in the treatment of HIV over the long term. VCT in adults has been linked to a reduction in HIV risk, safer sexual practices, and the use of support services (Doskoch, 2011). For VCT to be effective, confidentiality, respect for persons' rights, and ethical conduct by staff must be present to build trust, which is a cornerstone of the VCT program (Ratna \& Rifkin, 2007). Use of VCT services varies in communities because of barriers to access, society norms, and stigma (Hendriksen et al., 2009). The requirement that persons under 18 years must obtain parental consent to obtain an HIV test in Trinidad is a barrier to access. Improved communication and repeated testing allows individuals to know their status and to improve decision-making. UNAIDS (2014) reported, "Of the 35 million people living with HIV in the world, 19 million do not know their HIV-positive status" (Foreword). 
Eight students indicated they became sexually active because they felt pressured to do so. Six of these respondents were female and two were male. Adolescents often experience peer pressure by the need to belong to a group (Selikow et al., 2009). Childs and Sullivan (2013) posited that family conditions and problems in adjusting psychologically and socially could result in risky behavior that negatively affects sexual health in young adults. Not only does an individual's decision to engage in risky sexual activities, but also social interactions influence the spread of HIV/AIDS (Graffigna \& Olson, 2009).

Sixty-three percent of the participants reported that HIV/AIDS had not affected their lives in any way with 20 participants indicating that they did not know anyone with HIV/AIDS. Not knowing someone seemed to provide a shield of immunity event though some of the participants were sexually active. Graffigna and Olson (2009) found that youths in Canada developed a mechanism to handle the incurable nature of the disease by denying the importance of HIV/AIDS in their everyday lives. Individual denial negates mass media HIV messages and reduces the effectiveness of behavior change programs. Studies have shown that risk taking and a feeling of invincibility is a part of adolescence and must be considered when developing prevention programs for youth (Hoffman, 2010; Sambisa, Curtis, \& Stokes, 2009). The findings support the concepts of the denial of the importance of HIV/AIDS in youths' everyday lives, the willingness to take risk, and their feelings of invincibility. Only if the youths had a close relationship with someone with HIV/AIDS did they feel an impact on their life. Studies have reported that feelings of vulnerability increase when one knows someone who has HIV/AIDS or who has died from AIDS (Halperin et al., 2011).

Parents play an important role in HIV/AIDS prevention (Voisin \& Bird, 2009). Effective communication is an important factor in reducing high-risk sexual behavior (Pick, Givaudan, Sirkin, \& Ortega, 2007). Improving parent-adolescent communication skills on sexual risk can assist in HIV prevention (Villarruel, Cherry, Cabriales, Ronis, \& Zhou, 2008). Receiving information from parents and religious leaders contributes to a delay in having sex relations (Bleakley, Hennessy, Fishbein, \& Jordan, 2009). Participants indicated that closeness of their family unit, along with discussions with their parents were important in their decision to abstain from sexual activity. These findings were consistent with research by Voisin and Bird (2009) who concluded that adolescents under parental supervision and protection are dissuaded from engaging in risky sexual behavior. Parents play an important role in HIV/AIDS prevention. In the literature, communication has been identified as an important factor in reducing high-risk sexual behavior (Pick et al., 2007). Improving parent-adolescent communication skills on sexual risk can assist in HIV prevention (Villarruel et al., 2008). Receiving information about HIV/Aids prevention from parents and religious leaders can delay adolescents from having sex (Bleakley et al., 2009).

Trinidad is at a critical point in fighting the HIV/AIDS epidemic and key components of the implementation efforts require strengthening prevention programs with reduced external funding (World Bank Organization, 2010). Policy makers need to maximize the money spent in prevention efforts and not the lose ground gained in previous years. Internet technology can play an important part in communication for public health interventions. Students use the Internet for HIV information. Government leaders should consider the use of technology such as social media, texting, and the Internet to disseminate and collect HIV/AIDS information.

Tobago, the sister island of Trinidad, may benefit by conducting a similar study to ensure that policy decisions and social marketing programs adequately address the issues faced by teens in both islands. The students who participated in the present study were located in urban areas. A similar study might be conducted in rural areas where different socio-economic issues exist. Individuals in a low socio-economic status may engage in sexual activity early because of the need for economic survival. Socio-economic conditions can affect when first intercourse occurs (Tenkorang, Rajulton, \& Maticka-Tyndale, 2009). Persons who have sexual intercourse at an early age are less likely to know how to prevent HIV and how to use condoms effectively.

\section{References}

Benefo, D. K. (2010). Determinants of condom use in Zambia: A multilevel analysis. Studies in Family Planning, 4l(1), 19-30. http://dx.doi.org/10.1111/j.1728-4465.2010.00221.x

Bleakley. A., Hennessy M., Fishbein, M., \& Jordan, A. (2009). How sources of sexual information relate to adolescents' beliefs about sex. American Journal of Health Behavior, 33, 37-48. http://dx.doi.org/10.5993/AJHB.33.1.4

Bongaarts, J. (2007). Late marriage and the HIV epidemic in Sub-Saharan Africa. Population Studies, 61(1), 73-83. http://dx.doi.org/10.1080/00324720601048343 
Childs, K. K., \& Sullivan, J. C. (2013). Investigating the underlying structure and stability of problem behaviors across adolescence. Criminal Justice and Behavior, 40, http://dx.doi.org/10.1177/0093854812460496

DiClemente, R. J., Wingood, G. M., Crosby, R. A., Sionean, C., Cobb, B. K., Harrington, K., ... Oh, M. K. (2002). Sexual risk behaviors associated with having older sex partners: A study of Black adolescent females. Sexually Transmitted Diseases, 29, 20-24. http://dx.doi.org/10.1097/00007435-200201000-00004

Doskoch, P. (2011). Personal, national income positively linked to rates of voluntary HIV testing. International Perspectives on Sexual and Reproductive Health, 37, 219-220. http://dx.doi.org/10.1363/4326511

Graffigna, G., \& Olson, K. (2009). The ineffable disease: Exploring young people' s discourses about HIV/AIDS in Alberta, Canada. Qualitative Research, 19, 790-801. http://dx.doi.org/10.1177/1049732309335393

Halperin, D. T., Mugurungi, O., Hallett, T. B., Muchini, B. Campbell, B., Magure, T., ... Gregson, S. (2011). A surprising prevention success: Why did the HIV epidemic decline in Zimbabwe. PLoS Med, 8(2). http://dx.doi.org/10.1371/journal.pmed.1000414

Haque, M., R., \& Soonthorndhada, A. (2009). Risk perception and condom-use among Thai youths: Findings from Kanchanaburi demographic surveillance system site in Thailand. Journal of Health Population and Nutrition, 27, 772-783.

Hendriksen, E. S., Hlubinka, D., Chariyalertsak, S., Chingono, A., Gray, G., Mbwambo, J., ... Coates, T. J. (2009). Keep talking about it: HIV/AIDS-related communication and prior HIV testing in Tanzania, Zimbabwe, South Africa and Thailand. Aids Behavior, 13, 1213-1221. http://dx.doi.org/10.1007/s10461-009-9608-0

Hoffman, B. (2010). Teen drivers: Inherent risks, protection strategies. Pediatric Annals, 39(11), 703-708. http://dx.doi.org/10.3928/00904481-20101013-08

National AIDS Coordinating Committee. (2009). National HIV and AIDS spending assessment 2002-2006. Retrieved from https://www.unaids.org/en/media/unaids/contentassets/dataimport/pub/report /2009/nasa_trinidadand tobago_02 3040506_08082009_en.pdf

Office of the Prime Minister, Republic of Trinidad and Tobago. (2003). Five-year national HIV/AIDS strategic plan, January 2004-December 2008. Retrieved from http://hivaidsclearing house.unesco.org/search/resources /6980_National_Strategic_Plan-NACC.pdf

Pick, S., Givaudan, M., Sirkin, J., \& Ortega, I. (2007). Communication as a protective factor: Evaluation of a life skills HIV/AIDS prevention program for Mexican elementary school students. AIDS education and Prevention, 19, 408-421. http://dx.doi.org/10.1521/aeap.2007.19.5.408

Ratna, J., \& Rifkin, S. B. (2007). Equity, empowerment and choice: From theory to practice in public health. Journal of Health Psychology, 12, 517-530. http://dx.doi.org/10.1177/1359105307076238

Reid, S. A., Nielsen, A. L., \& Reddock, R. (2010). Changes in HIV needs identified by the National Aids Hotline of Trinidad and Tobago. Rev Panam Salud Publica, 27, 93-102. http://dx.doi.org/10.1590/S1020-49892010000200002

Romero, L. S., Ellis, A. A., \& Gurman, A. T. (2012). Disconnect between discourse and behavior regarding concurrent sexual partnerships and condom use: Findings from a qualitative study among youth in Malawi. Global Health Promotion, 19(4), 20-28. http://dx.doi.org/10.1177/1757975912464249

Saldana, J. (2009). The coding manual for qualitative researchers. Thousand Oaks, CA: Sage.

Sambisa, W., Curtis, S. L., \& Stokes, C. S. (2009). Ethnic differences in sexual behavior among unmarried adolescents and young adults in Zimbabwe. Journal of Biosocial Science, 42, 1-26. http://dx.doi.org/10.1017/S0021932009990277

Schaalma, H., Aaro, L. A., Fisher, A. J., Matthews, C., Kaaya, S., Onya, H., ... Klepp, K. (2009). Correlates to intention to use condoms among Sub-Saharan African youth: The applicability of the theory of planned behavior. Scandinavian Journal of Public Health, 37(Suppl 2), 87-91. http://dx.doi.org/10.1177/1403494808090632

Selikow, T., Ahmed, N., Fisher, A. J., Matthews, C., \& Mukoma, W. (2009). I am not "umqwayito": A qualitative study of peer pressure and sexual risk behavior among young adolescents in Cape Town, South Africa. Scandinavian Journal of Public Health, 37(Suppl 2), 107-112. http://dx.doi.org/10.1177/1403494809103903 
Sinding, S. W. (2005). Does CNN (condoms, needles and negotiation) work better than ABC (abstinence, being faithful and condom use) in attacking the AIDS epidemic? International Planning Perspectives, 31(1), 38-40. Retrieved from http://www.guttmacher.org/pubs/journals /3103805.html

Tenkorang, E. Y., Rajulton, F., \& Maticka-Tyndale, E. (2009). Perceived risks of HIV/AIDS and first sexual intercourse among youth in Cape Town, South Africa. AIDS Behavior, 13, $234-245$. http://10.1007/s10461-008-9470-5UNAIDS

Villarruel, A. M., Cherry, C. L., Cabriales, E. G., Ronis, D. L., \& Zhou, Y. (2008). A parent-adolescent intervention to increase sexual risk communication: Results of a randomized controlled trial. AIDS Education and Prevention, 20, 371-383. http://dx.doi.org/10.1521/aeap.2008.20.5.371

Voisin, D. R., \& Bird, J., D. (2009). What African American male adolescents are telling us about HIV infection among peers: Cultural approaches for HIV prevention. Social Work, 54, 201-211. http://dx.doi.org/10.1093/sw/54.3.201

World Health Organization. (2006). Preventing HIV/AIDS in young people: A systematic review of the evidence from developing countries. $\quad$ Retrieved from http://www.unicef.org/aids/files/PREVENTING_HIV_AIDS_IN_YOUNG_PEOPLE_A_SYSTEMATIC_ REVIW_OF_THE_EVIDENCE_FROM_DEVELOPING_CŌUNTRIES_W WHO_2006.pdf

\section{Copyrights}

Copyright for this article is retained by the author(s), with first publication rights granted to the journal.

This is an open-access article distributed under the terms and conditions of the Creative Commons Attribution license (http://creativecommons.org/licenses/by/3.0/). 